\title{
As (des)classificaçóes do tempo: linguagens teóricas, historiografia e normatividade
}

\author{
Rodrigo Turin ${ }^{*}$
}

Universidade Federal do Estado do Rio de Janeiro, Rio de Janeiro-RJ, Brasil

\section{RESUMO}

Nas últimas décadas, as reflexóes em torno da temporalidade passaram a ocupar um lugar de destaque na agenda de pesquisas historiográficas. O objetivo deste artigo é, justamente, propor um exercício de leitura, expresso em uma breve análise comparativa, de duas propostas teóricas que têm encontrado ressonâncias nessa agenda: a de François Hartog, centrada nas categorias de "regimes de historicidade" e de "presentismo"; e a de Hans Ulrich Gumbrecht, centrada principalmente nas categorias de "cronótopo", "presente lento" e "latência". Ainda que essas categorias apareçam por vezes intercambiadas em alguns textos e debates, elas guardam diferenças importantes, tanto no que diz respeito aos seus pressupostos epistemológicos (ou ontológicos) e alcances heurísticos, como nas formas de encaminharem seus diagnósticos e prognósticos das experiências contemporâneas, incidindo em duas posturas disciplinares e éticas distintas.

Palavras-chave: Teoria da História; temporalidade; historiografia.

\section{ABSTRACT}

In the past few decades, reflections on the subject of temporality have come to stand out in the historiographic research agenda. This paper aims to perform a comparative analysis of two theoretical proposals which have found repercussions in that agenda: François Hartog's, which concentrates in the categories of "historicity regimes" and "presentism," and Hans Ulrich Gumbrecht's, mainly focused on the categories of "chronotope," "slow present," and "latency." Although these categories are sometimes used interchangeably in some texts and debates, they yield important differences, regarding their epistemological (or ontological) foundations and heuristic scope, as well as the manner in which they deliver their diagnosis and prognosis of contemporary experiences, resulting in distinct disciplinary and ethical stances.

Keywords: Theory of History; temporality; historiography.

DOI - http://dx.doi.org/10.1590/2237-101X017033012

Artigo recebido em 5 de maio de 2016 e aprovado para publicação em 27 de julho de 2016.

* Professor no Departamento de História da Unirio. E-mail: rodrigoturin@gmail.com. 


\section{Sintomas e diagnósticos}

Nas últimas décadas, as reflexóes em torno da temporalidade passaram a ocupar um lugar de destaque na agenda de pesquisas da história da historiografia e da teoria da história. Expressōes como "o futuro não é mais o que era", "o passado que não passa" ou, ainda, um "presente que tudo consome", acionadas por diferentes autores, inserem-se hoje, de maneiras diferentes, como novos topoi em reflexóes acerca de nossa experiência temporal. ${ }^{1}$ Este fenômeno não deixa de estar ligado, por um lado, a uma dinâmica interna da disciplina. As críticas às metanarrativas que organizavam ( $\mathrm{e}$, em boa parte, ainda organizam) os currículos e as pesquisas historiográficas, os ataques da chamada "virada linguística" às pretensôes fundacionais da representação histórica, as denúncias e inversôes levadas a cabo por autores pós-colonialistas, assim como as novas demandas de uma história global, ou mesmo de uma "big history", estão levando, de um modo ou de outro, a uma corrosão da instrumentalidade de um tempo linear e homogêneo que presidiria, em boa medida, o trabalho historiográfico.

Soma-se a esses fatores a desestabilização institucional que vem afetando a disciplina histórica no sistema escolar. Se a sua institucionalização esteve fortemente vinculada à função de elaboração e divulgaçáo, via ensino, de determinada consciência histórica que, ao mesmo tempo, dava sentido e legitimava a existência e a soberania dos estados-naçáo, hoje cada vez menos esses estados precisam assentar-se em uma suposta consciência histórica comum a seus cidadãos. Não por acaso, diferentes projetos de reforma do ensino, seja na Europa, na Ásia ou nas Américas, têm diluído a posição da disciplina histórica em seus currículos em função do desenvolvimento do que vem sendo denominado de "competências básicas", centradas no domínio da língua e da matemática, necessárias a um mercado cada vez mais "dinâmico" e no qual os sujeitos têm que se mostrar cada vez mais "flexíveis". ${ }^{2}$ No que diz respeito à antiga função de elaboração de uma identidade histórica, cada vez mais esse papel vem sendo desempenhado no fórum da "história pública", onde historiadores profissionais convivem e disputam com diversos outros agentes e mídias a elaboração de narrativas e representaçóes históricas direcionadas, agora, a uma pluralidade de identidades e a novas demandas de memória. ${ }^{3}$

Para além desses fatores vinculados à dinâmica disciplinar, outro elemento que parece estar ligado ao crescente interesse pela temporalidade é a elaboração de diagnósticos acerca de experiências sociais e políticas contemporâneas, as quais indicariam seja uma crise das

\footnotetext{
${ }^{1}$ Para uma visão geral dessas discussóes, cf. LORENZ, Chris; BEVERNAGE, Berber (Orgs.). Breaking up time. Negotiating the borders between present, past and future. Gottingen: Vandenhoeck \& Ruprecht, 2013. ${ }^{2}$ LORENZ, Chris. If You're So Smart, Why Are You under Surveillance? Universities, Neoliberalism, and New Public Management. Critical Inquiry, n. 38, 2012.

${ }^{3}$ NOIRET, Serge. História pública digital. Liinc em Revista, Rio de Janeiro, v. 11, n. 1, p. 28-51, maio 2015; GROOT, Jerome de. Consuming history. Historians and Heritage in Contemporary Popular Culture. Abingdon: Routledge, 2008.
} 
categorias temporais sedimentadas socialmente (e/ou intelectualmente), seja mesmo uma nova forma de relação com o tempo. Os efeitos da Segunda Guerra e, mais especificamente, do Holocausto em vários âmbitos da cultura contemporânea; a queda do Muro e a dita falência do projeto comunista; a difusão e os efeitos das novas tecnologias e sua nova "realidade virtual"; as diversas demandas por memória e as políticas de patrimonialização; a crise ambiental e "os medos dos fins"; todos esses são apenas alguns dos marcos referenciais que são comumente associados, de modos e com sentidos distintos, a uma necessária reflexão ou mesmo reorientação de nossa experiência do tempo.

No contexto dessas transformações disciplinares e sociais, tem-se fomentado a elaboração de categorias que permitam tanto a investigação das diferentes configuraçóes entre tempo e escrita da história, resultando em e alimentando-se de distintas narrativas da história da historiografia e/ou da modernidade, como também critérios para a elaboração daqueles diagnósticos e, em alguns casos, prognósticos referentes à contemporaneidade. Tais propostas variam desde uma nova metafísica do tempo, como assinalada em recente número da revista History and Theory, na qual se procura (re)definir a natureza de nossa relação com as dimensôes do passado, presente e futuro, como também reflexões mais propriamente epistemológicas e éticas, as quais se voltam ao caráter performativo (e político) das diferentes linguagens temporais. ${ }^{4}$

O objetivo deste artigo é, justamente, propor um exercício de leitura, expresso em uma breve análise comparativa, de duas propostas teóricas que têm encontrado ressonâncias nessa agenda: a de François Hartog, centrada nas categorias de "regimes de historicidade" e de "presentismo"; e a de Hans Ulrich Gümbrecht, centrada principalmente nas categorias de "cronótopo", "presente lento" e "latência". Ainda que essas categorias apareçam por vezes intercambiadas em alguns textos e debates, elas guardam diferenças importantes, tanto no que diz respeito aos seus pressupostos epistemológicos (ou ontológicos) e alcances heurísticos, como nas formas de encaminharem seus diagnósticos e prognósticos das experiências contemporâneas, incidindo em duas posturas disciplinares e éticas distintas. Enquanto a proposta de Gumbrecht insere-se, de um modo ou de outro, mais próxima às reflexóes vinculadas à definição de uma ontologia temporal, a de Hartog pode ser incluída como exemplo de uma reflexão de caráter mais epistemológico e voltada à dimensão dos usos e dos efeitos éticos das linguagens temporais. Outros autores, com diferentes perspectivas, poderiam ser incluídos nesta análise comparativa; e sua posterior inserção com certeza enriqueceria e complexificaria a reflexão. No entanto, esta seleção se deve em parte pelo fato de que os dois autores mencionados encontram no mercado historiográfico brasileiro, especificamente, uma acentuada circulação; além disso, creio que algumas das consideraçóes retiradas desse exercício comparativo possa estender-se a outros trabalhos, ainda que com matizes distintos.

\footnotetext{
${ }^{4}$ KLEINBERG, Ethan. Introduction: the new metaphysics of time, History and Theory, virtual issue, n. 1, August, 2012.
} 
O objetivo não é desenvolver uma análise pormenorizada de ambos, já em parte realizada, mas entender, a partir de suas diferentes formas de argumentaçấo, qual a economia de funcionamento dessas categorias em seus textos, compreendendo-as como dois modos distintos de lidar com a linguagem teórica de descrição do mundo e, mais especificamente, de pensar o tempo e escrever a história.

\section{Gumbrecht, clima histórico e o presente lento}

A produção de Hans Ulrich Gumbrecht é bastante vasta e complexa. Não seria possível, aqui, retomar todas as mudanças e modulaçóes presentes em sua obra, desde os trabalhos inseridos na agenda da estética da recepção até as reflexôes atuais acerca da "produção de presença" e do "clima histórico". Contudo, não é possível tematizar sua obra mais recente, que será aqui privilegiada, sem relacioná-la à sua trajetória intelectual. Até porque essa relação é recorrente e enfaticamente realizada pelo próprio Gumbrecht em seus últimos escritos, constituindo parte importante de seu estilo argumentativo. A narrativa autobiográfica, o recurso à autoridade testemunhal, o argumento geracional, mais do que caprichos ou excentricidades (diante dos padrôes acadêmicos mais comuns), devem ser entendidos como partes constituintes e fundamentais de seu projeto intelectual. Forma e conteúdo, como sempre, se condicionam mutuamente. Esses elementos autobiográficos dizem respeito, acima de tudo, a uma ênfase no caráter que poderíamos chamar de "experiencial" que sua escrita quer revelar e explorar. Este caráter experiencial define-se, por sua vez, essencialmente em oposição àquilo que ele identifica como uma marca negativa que dominou as ciências humanas desde o século XIX: a ênfase no sentido e a multiplicação dos protocolos interpretativos que regravam as produçóes acadêmicas. Contra essa dimensão hermenêutica das ciências humanas, que resultaria, segundo o autor, em uma profusão de interpretaçôes equivalentes e em um consequente afastamento ou uma perda do mundo, Gumbrecht busca revalorizar uma dimensão experencial não hermenêutica (distinta, portanto, da dimensão experencial gadameriana), vinculada às materialidades que conformariam o lado ignorado ou esquecido por aquela tradiçấo. ${ }^{5}$

Assim, esse investimento experencial, permeado pelo elemento autobiográfico, cujo ápice encontra-se em seu livro Depois de 1945, busca assumir uma representatividade que extrapola a dimensão propriamente individual, reivindicando um caráter sintomático tanto para as ciências humanas, em particular, como para a sociedade contemporânea como um todo. Sua formação no ambiente pós-guerra alemão, a participação no projeto da história dos

\footnotetext{
${ }^{5}$ A elaboração e o desenvolvimento desse argumento estrutural podem ser encontrados em GUMBRECHT, Hans Ulrich. Depois de aprender com a história. In: Em 1926. Vivendo no limite do tempo. Rio de Janeiro: Record, 1999; Cascatas da modernidade. In: Modernização dos sentidos. São Paulo, Editora 34, 1998; Production of presence. What meaning cannot convey. Stanford: Stanford Universitty Press, 2004.
} 
conceitos, a desilusão ao descobrir o engajamento de seu ex-orientador no regime nazista (que indicaria, ao mesmo tempo, a falta de enfrentamento desse passado por parte dos historiadores envolvidos no projeto hermenêutico da história dos conceitos) e, por fim, a tomada de consciência do suposto esgotamento e crise daquele projeto epistemológico, são algumas das evidências experenciais que, em sua argumentação, levariam a uma necessária reformulaçấo da agenda das humanidades. O enredo desse relato autobiográfico, que se replica em diferentes textos e entrevistas, assim como na própria capa de um de seus livros mais importantes, constitui-se como um argumento central em sua produçáo mais recente, em torno do qual outros exemplos giram e vêm agregar-se.

Em paralelo a essa narrativa autobiográfica, mas complementar a ela, está uma leitura da epistemologia moderna, denominada às vezes de "cartesiana". Essa leitura tem por fim destacar o processo autodestrutivo de conformaçáo de um sujeito de conhecimento que vai se dobrando sobre si mesmo, no mesmo movimento em que se afasta do mundo. É o que Gumbrecht denomina de "observador de primeira ordem" e "observador de segunda ordem", que configurariam as bases de um cronótopo moderno historicista, no qual o sujeito se entende como inserido em um processo de permanente mudança. ${ }^{6}$ Esse processo crescente de perspectivaçáo e temporalizaçáo acabaria resultando em uma crise da representação, expressa sintomaticamente nos vários modernismos do início do século XX assim como, no caso das ciências humanas, na virada linguística das décadas de 1970 e 1980 . O ocaso da história dos conceitos, tal como ele o insere em sua narrativa, estaria vinculado justamente a esse contexto, denunciado no que denomina de uma indecisão fundamental "em relação ao problema da referência ao mundo da linguagem". ${ }^{7}$ Sem ter enfrentado realmente o problema da relação entre linguagem e mundo, ou mantendo uma ambivalência entre eles, o projeto da história dos conceitos estaria fadado a um esmorecimento. O sentido final desse processo histórico-epistemológico por ele evocado se resumiria, enfim, em três elementos correlatos que definiriam nosso presente epistemológico: desreferencializaçáo, destemporalização, dessubjetivação. O efeito mais sintomático disso seria o que Gumbrecht denomina de "nosso presente ampliado ou estendido", "pleno de simultaneidades". Em suas palavras: "Em vez de em constante transiçáo, sentimo-nos encerrados em um presente complexo, que abarca todos os passados e recusa o futuro, e em relação ao qual parece não estar mais à nossa disposição qualquer perspectiva externa". 8

Não por acaso, Gumbrecht encontrou na filosofia de Heidegger uma forte orientação para sua reflexão mais recente, principalmente após a publicação do livro Em 1926. A partir dali, tanto a leitura daquele processo epistemológico ocidental, entendido também como

\footnotetext{
${ }^{6}$ GUMBRECHT, Hans Ulrich. Cascatas da modernidade, op. cit., p. 14-15.

${ }^{7}$ GUMBRECHT, Hans Ulrich. Pirâmides do espírito. Sobre a rápida ascensão, as dimensôes invisíveis e o súbito esmorecimento do movimento da história dos conceitos. In: GUMBRECHT, Hans Ulrich. Graciosidade e estagnação. Ensaios escolhidos. Rio de Janeiro, Contraponto/PUC-Rio, 2012.

${ }^{8}$ Ibidem, p. 56.
} 
uma metafísica da subjetividade, quanto as chaves de sua superação passaram a ancorar-se em sua leitura de certas proposiçóes da ontologia fundamental heideggeriana, sustentando, assim, as concepções de historicidade que suas categorias buscam tematizar. É importante notar, nesse sentido, essa forte correlação entre a narrativa da teoria e uma teoria para a narrativa. Ou seja, concatenado ao modo de ler aquele processo de crise da representação ocidental, pautada em uma metafísica da subjetividade (agora informada pela filosofia heideggeriana), está a definição de pressupostos ontológicos que servem, ao mesmo tempo, de orientação normativa à superação daquela crise. Tais pressupostos indicariam o que qualificaria a falta, ou carência, responsável por causar o mal-estar geracional antes referenciado em sua narrativa autobiográfica, expressando-se em um "desejo" não satisfeito pelo passado e, em sentido mais geral, pela própria substancialidade do mundo. Em suas palavras: "Esta falta torna fácil perceber que aquilo que nos orienta especificamente em direção ao passado é o desejo de atravessar o limite que separa nossas vidas do tempo anterior ao nosso nascimento. Queremos conhecer os mundos que existiam antes que tivéssemos nascido, e ter deles uma experiência direta"?

Esse desejo ontológico por uma experiência direta do passado, não podendo ser suprido pelas contínuas e equivalentes produçôes de sentido oferecidas pelas ciências humanas, necessita encontrar novas categorias a partir das quais possa ser tematizado e realizado. É aqui que a dimensão metafórica do "habitar o mundo" heideggeriano, como modalidade do Dasein, surge como uma via alternativa (ou de superação) aos limites hermenêuticos estabelecidos pelas ciências humanas. O que interessa a Gumbrecht é, acima de tudo, a qualidade espacial dessa caracterização do Ser por Heidegger: a qualificação da existência humana como um "estar-no-mundo", mais especificamente, como uma existência que está sempre já em um contato substancial e espacial com as coisas do mundo, antes de tornar-se "cultura". 10 E a esse estar-no-mundo se agrega, na filosofia tardia heideggeriana, a identificação de uma carência pela autenticidade da morada do ser, resultado de um ocultamento da/na linguagem e que se expressa em uma necessidade de sempre ter que aprender de novo a habitar o mundo. É justamente nessa chave de desvelar o que está ocultado pela linguagem (no caso, da linguagem inautêntica das humanidades, porque supostamente objetificante), e com isso de indicar a autenticidade dessa carência pela morada do ser, que o projeto de Gumbrecht se desenha. ${ }^{11}$

As categorias que Gumbrecht vem propondo em seus últimos trabalhos, como "produção de presença", "clima”, Stimmung e "latência", buscam justamente abarcar, ao mesmo

\footnotetext{
${ }^{9}$ GUMBRECHT, Hans Ulrich. Depois de aprender com a história, op. cit., p. 467.

${ }^{10}$ GUMBRECHT, Hans Ulrich. Production of presence, op. cit., p. 66.

${ }^{11}$ HEIDEGGER, Martin. Construir, habitar, pensar. Córdoba: Alción, 1997, p. 57. Uma abordagem semelhante de voltar a historiografia a esse desvelamento de ser, em diferenciação a uma linguagem objetificante ou contextualizante da historiografia, pode ser encontrada em ARAÚJO, Valdei Lopes de. A história da historiografia como analítica da historicidade. História da Historiografia, Ouro Preto, n. 12, 2013.
} 
tempo que pressupóe, essa dimensão ontológica, espacial e substancial com o mundo. E em seu livro Depois de 1945 ele busca dar uma expressão historiográfica a esse projeto. Em torno do fio narrativo autobiográfico, alguns textos e exemplos são lidos sob aquela perspectiva ontológica, buscando identificar os sintomas de "latência" do pós-guerra e, com isso, a emergência de "nosso presente estendido". O conceito de "latência", segundo ele, tem por finalidade indicar uma certa "disposição geral", manifestando-se de modo mais ou menos semelhante ao passageiro clandestino de Eelco Runia: algo que está lá, manifesta-se nas coisas que nos cercam ou no que é dito, mas não podemos identificar claramente. ${ }^{12}$ Como diz Gumbrecht: "É impossível dizermos com precisão de onde nos vem a certeza dessa presença, tampouco sabemos afirmar exatamente onde está agora aquilo que é latente". ${ }^{13}$ Esta proposição é exemplificada, em seguida, com algumas revistas do pós-guerra, cujas fotos de uma erupção vulcânica ou propagandas de lâminas de barbear associadas a peles de bebês desvelariam a atmosfera latente de violência então experimentada. São imagens que expressam intencionalmente determinado sentido, mas guardariam em si (ou melhor, em sua materialidade) uma presença escamoteada que ele, Gumbrecht-narrador, tenta desvelar ao leitor. Outro exemplo mencionado são os escritos de Carl Schmitt e do ficcionista afro-americano Ralph Ellison, que, apesar de suas experiências bastante distintas (o primeiro, um nazista semissegregado após a derrota alemã; o segundo, um novelista negro escrevendo acerca das discriminaçóes étnicas e sociais nas cidades norte-americanas), acabariam por desvelar uma mesma disposição global daquele presente: o sentimento de estar-fora-do-mundo. Como afirma o próprio Gumbrecht, não há nada ali que possa indicar claramente ou controlar essa identificação da latência que uniria os exemplos citados (não, pelo menos, no que constitui a tradição da linguagem das ciências humanas). Para ele, o que permite essa identificação, no limite, são os próprios objetos que "nos" afetariam de um modo corpóreo, "na medida em que faz despertar em nós sentimentos de desconforto para os quais dificilmente temos conceitos descritivos". ${ }^{14}$ Em que medida, no entanto, isso é um efeito real dos objetos ou uma disposição do próprio autor, que se universaliza em um "nós" indefinido, fica à (in)decisão do leitor acatar ou não. De todo modo, uma das objeçóes que podem ser feitas a esse exercício (que não deixa de ser, ao final, hermenêutico) é em que medida o uso dessas categorias propostas, mais do que se mostrar como uma superação à produção excessiva de sentido, não acabaria gerando justamente aquilo que denuncia.

Ou seja, um dos grandes problemas dessa proposta, me parece, é em que medida essas categorias podem ser trabalhadas e estendidas a novas análises sem que se limitem ao mesmo tipo de argumentação intuitiva, universalizando uma disposição particular e, com isso, pro-

\footnotetext{
${ }^{12}$ RUNIA, Eelco. Presence. In: RUNIA, Eelco. Moved by the Past. Discontinuity and historical mutation. Nova York: Columbia University Press, 2014.

${ }^{13}$ GUMBRECHT, Hans Ulrich. Depois de 1945. Latência como origem do presente. São Paulo: Unesp, 2012, p. 40.

${ }^{14}$ Ibidem, p. 42, grifo nosso.
} 
duzindo uma profusão de sentidos arbitrários; ou se, ao contrário, elas não funcionam senão sob essa economia intuitiva da escrita proposta por Gumbrecht e que se manifesta em seu estilo argumentativo. No geral, ainda que possam resultar em bons insights ou em leituras atraentes, o uso dessas categorias parece oferecer poucas medidas de controle que possam ajudar o leitor a submeter as afirmaçóes a uma vulnerabilidade empírica qualquer. Elas acabam assumindo em seus textos, em grande medida, um caráter fortemente impressionista. $\mathrm{Na}$ economia de seu texto, a autoridade testemunhal se desloca para a autoridade do leitor, que é chamado a referendar a leitura por uma espécie de identificação empática engrendrada pelo próprio texto. Todos os exemplos, nessa chave, vêm ilustrar o diagnóstico já formado, submetendo experiências distintas a um mesmo padrão de sentido (ou, no caso, de "presença"). Não encontramos em seus textos, por exemplo, a exploração de contraexemplos a partir dos quais as categorias e as hipóteses pudessem ser testadas e complexificadas. As noçốes de "clima" e "latência" acabam se tornando recursos hermenêuticos para transformar os diferentes exemplos em índices de um enredo narrativo já pressuposto (no caso, a emergência de nosso "presente lento"). Todos os mecanismos estilísticos que Gumbrecht veio desenvolvendo em seus últimos textos confluem, assim, com as proposiçóes teóricas que suas categorias ao mesmo tempo pressupóem e visam abarcar, expressando-se na produçáo de uma proximidade entre autor e leitor, e no efeito de presença entre leitor e o passado. Ao final, poderíamos perguntar em que medida esse "desejo" por um contato direto com o passado pode qualificar um dado ontológico original, ou, ao contrário, diz respeito antes à disposição de uma experiência particular, a um tipo de trajetória específica? Esta pergunta nos levaria, no entanto, a uma dimensão hermenêutica (e sociológica) que é justamente recusada por essa proposta. De todo modo, não é possível entender e usar essas categorias sem ter em mente que elas implicam, ao mesmo tempo, determinados pressupostos ontológicos e uma consequente normatividade acerca do fazer das humanidades e, mesmo, de como "estar no tempo".

\section{Hartog, regimes de historicidade e presentismo}

Autor igualmente familiar aos historiadores brasileiros, François Hartog vem se dedicando há já três décadas a uma reflexão sobre as relaçôes entre experiências do tempo e escrita da história. Emblemas maiores dessa reflexão, mas não os únicos, são as noções por ele desenvolvidas, e hoje já bastante difundidas, de "regimes de historicidade" e de "presentismo". Para os fins da leitura comparativa aqui empreendida, é sobre a forma e o uso dessas categorias, tal como aparecem em seus textos, que me concentrarei, delimitando brevemente algumas de suas características.

A primeira noção (regimes de historicidade) insere-se, como seu autor não cansa de reiterar, como um instrumento heurístico de caráter eminentemente comparativo, que permite 
identificar configuraçôes históricas da temporalidade, ou seja, as diferentes formas de relação entre passado, presente e futuro estabelecidas em diferentes sociedades. ${ }^{15}$ Formulada originalmente em um diálogo estreito com a antropologia, a categoria buscava, ao mesmo tempo, problematizar (desnaturalizando) as noçôes ocidentais modernas de um tempo progressivo e ofertar uma ferramenta a partir da qual a historicidade pudesse se tornar um objeto de investigação histórica. ${ }^{16}$ A segunda noção, a de "presentismo", pode ser entendida como um dos resultados do questionário aberto pela investigação dos diferentes regimes de historicidade, apresentando-se como uma chave de leitura e de reflexão sobre certos fenômenos do presente; o modo como a sociedade contemporânea, acima de tudo europeia e norte-americana, vem reconfigurando sua experiência temporal. Nesse sentido, é necessário frisar que, se a noção de presentismo resulta do uso de um instrumento heurístico e, portanto, pode ser compartilhada, estendida a novos casos e criticada, ela não deixa de ser também o sinal de uma inquietação que origina e justifica o próprio projeto historiográfico que Hartog vem desenvolvendo em seus últimos livros. O que gostaria de ressaltar com essa observação é o fato de Hartog também se explicitar em seus textos como observador do seu presente, ao mesmo tempo que busca elaborar, no entanto, ferramentas analíticas capazes tanto de controlar como potencializar a curiosidade desse olhar. Daí parece resultar, a meu ver, o que caracteriza um traço importante de seu estilo argumentativo. Dizendo de forma resumida: enquanto Gumbrecht busca, em seu estilo, produzir um efeito constante de presença (entre ele e o leitor, entre o leitor e o passado), a voz narrativa e as categorias acionadas por Hartog privilegiam antes produzir uma forma de distanciamento (daí a importância da metáfora da viagem e do olhar distanciado, para Hartog). Diferença que se ancora, justamente, em entendimentos distintos acerca da uso da linguagem e do modo de proceder das ciências humanas.

Em vários de seus textos, isso se mostra seja na recusa (e crítica) do recurso testemunhal, seja na própria disposição narrativa escolhida, produzindo idas e vindas constantes entre passado e presente. Seu ensaio sobre a relação entre o testemunho e o historiador é, nesse sentido, bastante sintomático. Ele inicia indicando determinados fenômenos presentes no cotidiano, a partir dos quais formula um diagnóstico (a forte difusão de formas testemunhais de relaçáo com o passado), para então voltar-se a diferentes configuraçôes históricas daquelas relaçóes, desenhando uma tipologia que vem ofertar um quadro de inteligibilidade para a leitura das experiências contemporâneas referidas de início, as quais podem ser lidas e problematizadas, então, a partir das dimensóes conflitivas das noçóes de autenticidade e

${ }^{15}$ HARTOG, François. Regimes de historicidade. Presentismo e experiências do tempo. Belo Horizonte: Autêntica, 2013.

${ }^{16}$ DELACROIX, Christian. Genealogie d'une notion. In: DELACOROIX, Christian; DOSSE, François; GARCIA, Patrick (Orgs.). Historicités. Paris, La Découverte, 2009; NICOLAZZI, Fernando. A História entre tempo: François Hartog e a conjuntura historiográfica contemporânea. História: Questóes \& Debates, Curitiba, n. 53, jul./dez. 2010. 
de veracidade. ${ }^{17}$ Sua predileção pelo trânsito constante entre antigos e modernos, em suas várias mediaçóes, se insere, igualmente, nessa estratégia de distanciamento, explorando as diferentes dimensôes comparativas e seus efeitos cognitivos. ${ }^{18}$

Essa atenção à abordagem comparativa, presente tanto em suas categorias como em suas análises, não deixa de remeter à especificidade de seu lugar de fala, e que ajuda a qualificar melhor os fundamentos que orientam seu projeto historiográfico. Se as concepçôes de linguagem e de historicidade de Gumbrecht reclamam a vinculação a uma determinada tradição hermenêutica alemã (ainda que para superá-la), assim como a referência central de Heidegger (que possibilitaria a superação), Hartog, a partir de interlocutores como Lévi-Strauss, Vernant, Gérard Lénclud e mesmo Marshall Sahlins, pode ser vinculado a uma certa tradição francesa das ciências sociais. ${ }^{19}$ Vale ressaltar, nesse sentido, que sua recepção de um autor como Koselleck é, em grande parte, mediada por tal tradição, não implicando (como já ressaltou Christan Delacroix) a incorporação de determinadas discussóes e pressupostos filosóficos que caracterizam a obra do historiador alemão. Ou seja, muito mais do que definir características meta-históricas da historicidade (como os pares antinômicos koselleckianos) ou ontológicas (como o ser-para-a-morte heideggeriano), presentes nos diálogos e debates que Koselleck trava com Schmitt, Gadamer e Heidegger, Hartog entende as categorias analíticas como instrumentos eminentemente heurísticos, portanto ferramentas que geram determinados efeitos de conhecimento, próximo ao modo como Jean-Claude Passeron sintetizou aquela tradição. ${ }^{20}$ Nesse sentido, ainda que o próprio Hartog não teça consideraçôes teóricas a respeito, a linguagem das ciências humanas em seus textos pode ser entendida, acima de tudo, como elaboraçóes protocolares de nossa linguagem natural (comunicativa) que possibilitam e, ao mesmo tempo, controlam determinadas formas de ver e ler experiências históricas. Visto sob esse viés quase pragmático da linguagem, presente também em outros interlocutores, como Jacques Revel, o uso das categorias não visa a definição de pressupostos ontológicos, mas serve como meio de investigação de fenômenos historicamente condicionados, entre eles as formas através das quais as sociedades estabelecem relações entre as dimensões do passado, presente e futuro. ${ }^{21}$ Se na noção de "presentismo",

\footnotetext{
${ }^{17}$ HARTOG, François. A testemunha e o historiador. In: HARTOG, François. Evidência da História. O que os historiadores veem. Belo Horizonte: Autêntica, 2011.

${ }^{18}$ Ver especialmente HARTOG, François. Anciens, Modernes, Sauvages. Paris, Galaade, 2005.

${ }^{19}$ Um marco inicial importante dessa tradição, caracterizado por uma relação de aproximação e distanciamento frente à filosofia do tempo bergsoniana, a partir da agenda da sociologia durkheiniana, e que formula problemas fundantes das posteriores pesquisas histórico-sociais da historicidade do tempo, é o texto de HUBERT, Henri. Estudo sumário da representação do tempo na religião e na magia. In: BENTHIEN, Rafael Faraco; PALMEIRA, Miguel; TURIN, Rodrigo (Orgs.). Estudo sumário da representação do tempo na religião e na magia. Coleção Durkheiniana, v. II. São Paulo: Edusp, 2016.

${ }^{20}$ PASSERON, Jean-Claude. O raciocínio sociológico. O espaço não popperiano do raciocínio natural. São Paulo: Vozes, 1995.

${ }^{21}$ Ver por exemplo REVEL, Jacques. Recursos narrativos e conhecimento histórico. In: História e Historiografia. Exercícios Críticos. Curitiba: Editora UFPR, 2010.
} 
particularmente, pode ser discutida uma dimensão valorativa, acredito ser um erro confundir, como o faz Delacroix, tal dimensão com a definição de alguma "natureza ontológica. ${ }^{22}$ Como dito anteriormente, se a busca pela categoria se origina de uma dimensão experiencial, sua formulação e alcance não implica, necessariamente, na pressuposição ou na delimitação de qualquer dimensão ontológica que a (des)qualifique as formas de experiência temporal socialmente configuradas (como o par autenticidade/inautenticidade heideggeriano). ${ }^{23}$

Essa distinção pode ficar mais clara ao compararmos os modos como nas linguagens de Gumbrecht e de Hartog se vinculam as interpretaçóes que realizam de fenômenos sociais e a forma como encaminham suas tomadas de posição frente às humanidades. Como vimos, um dos eixos narrativos elaborados por Gumbrecht para a orientação de suas categorias é a excessiva ou mesmo tirânica produção de sentido das ciências humanas, que resultaria em uma perda do mundo que deveria ser contrabalançada ou superada (há uma ambivalência entre as duas posições) pela dimensão da presença, reconfigurando o próprio lugar das humanidades. É uma espécie de sentido imanente do processo epistemológico moderno, informado pelos pressupostos ontológicos já descritos, que levaria, como por necessidade, ao ocaso de propostas como a história dos conceitos e ao surgimento de uma nova agenda. Ao mesmo tempo que aponta a insuficiência do cronótopo historicista em ofertar uma representação adequada do real, sua proposta teórica não deixa de sustentar-se fundamentalmente em esquemas narrativos deste mesmo cronótopo, desvelando um sentido único e imanente da História, que situam "o contemporâneo" em uma posição normativa. Os diagnósticos que Hartog elabora apontam para uma relação distinta. Sua leitura das expressóes historiográficas do regime moderno de historicidade, assim como das experiências denominadas de "presentistas", ainda que possam ser problematizadas (como veremos) por sugerir uma linearidade ou homogeneidade, não incidem em nenhum substrato universal ou ontológico que condicionaria uma normatividade ao presente. Se as categorias heurísticas permitem problematizar esses fenômenos, dotando-os de uma inteligibilidade relativa, as tomadas de posição são puramente valorativas e, portanto, políticas, em seu sentido mais amplo. Com isso, os efeitos teóricos e práticos dessas novas experiências náo podem ser previstos, muito menos instituídos por uma "ordem do tempo" qualquer (como o ocaso da história dos conceitos, já citado).

E nesse sentido, é importante ressaltar dois elementos que vêm sendo apontados a partir dos debates e usos daquelas categorias por Hartog, ambos envolvendo, justamente, o risco

\footnotetext{
${ }^{22}$ DELACROIX, Christian. Genealogie d'une notion, op. cit., p. 42.

${ }^{23}$ Concordo, nesse sentido, com a crítica de Blumenberg quanto à possibilidade mesma de enunciação das assertivas que sustentam a ontologia heideggeriana: "El problema sería: ¡como es que un ser calificado y definible por el cuidado, es decir, un ser para el que su propria existencia es primordial por ser el hecho menos seguro de su concencia, llega, no obstante, a la reflexión de sí mismo y de su estado? Se ve de inmediato que queda descartado cualquier respuesta que no subordine funcionalmente la reflexión al cuidado". "La pregunta no es cómo es posible la ontología sino cómo se llega a ella, porque se vuelve inexplicable por su origen genético, contradictoria por sua rango afirmado repentinamente". BLUMENBERG, Hans. Descripción del ser humano. México: Fondo de Cultura Económica, 2010, p. 154-155.
} 
de seu congelamento e universalização. O primeiro diz respeito à necessidade de explorar contraexemplos, evitando o risco de tornar as categorias de "regimes de historicidade" e de "presentismo" indexadores de épocas ou mentalidades homogêneas e sucessivas. Algo que se mostra nos textos de Hartog a partir da noção arendtiana de "brechas", ainda que tal noção não receba uma definição muito precisa, gerando ambiguidades. De todo modo, esta é uma agenda que ainda permanece largamente em aberto: investigar os modos de coexistência, os conflitos e as conexôes de distintos regimes de historicidade. ${ }^{24} \mathrm{Ou}$, ainda, investigar como a noçáo de regimes de historicidade nos permite pensar a relação fundamental entre forma e historicidade; ou seja, como os diferentes regimes de historicidade abarcam e possibilitam regimes historiográficos (ou gêneros discursivos) distintos. ${ }^{25} \mathrm{O}$ recente dossiê promovido pela revista Vingtième Siècle, sobre a coexistência e a concorrência de tempos na sociedade contemporânea, pode ser visto como um importante avanço nessa direção. ${ }^{26}$

O segundo elemento vincula-se à necessidade correlata de estabelecer distinçôes internas às categorias, e mais especificamente à categoria de "presentismo". Em que medida, por exemplo, é possível qualificar "nosso presente" como "presentista" (pleno ou de transição), tornando equivalentes experiências tão distintas como o "presentismo" do mercado financeiro, da experiência cotidiana dos desempregados, de diferentes projetos museográficos, das leis memoriais, entre outros? ${ }^{27} \mathrm{Ou}$, ainda, de que modo o questionário aberto pelas categorias permite compreender a relaçáo existente entre os processos hiperacelerados de nossa sociedade tecnológica e financeira, como apontados por Hartmut Rosa, com aqueles outros de "congelamento do tempo", como a proliferação de museus e as práticas patrimoniais? A hipótese aventada por Rosa, a partir de Lübbe, de um "princípio de compensação", acaba se mostrando um recurso frágil e de difícil comprovação, visando ainda manter alguma espécie de unidade essencial (quase psíquica) entre fenômenos tão heterogêneos. ${ }^{28}$ -

De modo similar ao que indicou Andreas Huyssen, mais do que condensar essas distintas experiências em classificaçóes unitárias, conviria antes desembrulhar essas diferenciaçôes temporais e espaciais, como condição para chegar a novos tipos de comparaçôes, ou conexôes, para além de velhas oposiçóes como antigo $\times$ moderno; centro $\times$ periferia; global

\footnotetext{
${ }^{24}$ BLOCKER, Déborah; HADDAD, Elie. Le présent comme inquiétude: temporalités, écritures du temps et actions historiographiques. Revue d'histoire moderne et contemporaine, n. 53, 2006.

${ }^{25}$ MUDROVCIC, María Inés. Regímenes de historicidad y regímenes historiográficos: del pasado histórico al pasado presente. In: Historiografías, Revista de Historia y Teoría, n. 5, 2013.

${ }^{26}$ BANTIGNY, Ludivine; DELUERMOZ, Quentin (Orgs.). Historicités du 20 siècle. Coexistence et concurrence des temps. Vingtième Siècle. Revue d'Histoire, n. 117, jan./mar. 2013.

${ }^{27}$ PEREIRA, Mateus Henrique de Faria; MATA, Sérgio da. Introdução: Transformaçôes da experiência do tempo e pluralização do presente, In: VARELLA, Flávia; MOLLO, Helena M; PEREIRA, Mateus H. de Faria; MATA, Sérgio (Orgs.). Tempo presente e usos do passado. Rio de Janeiro: FGV, 2012.

${ }^{28}$ ROSA, Hartmut. Accéleration. Une critique sociale du temps. Paris: La Découverte, 2010; ver também ROSA, Hartmut; SCHEUERMAN, William E. (Orgs.). High-speed society. Social acceleration, power and modernity. Philadelphia: Pennsylvania University Press, 2009.
} 
$\times$ local; linear $\times$ cíclico; ocidente $\times$ oriente; etc. ${ }^{29}$ Do mesmo modo, autores como Helge Jordheim vêm assinalando a necessidade de pensar as relações e as tensões entre a multiplicidade de tempos e os processos de sincronização estabelecidos entre eles por diferentes sociedades. ${ }^{30}$

Sem esse esforço de refinamento das ferramentas analíticas, corre-se o risco de tornar a expressão uma forma fácil de classificação, reproduzindo diagnósticos semelhantes sobre fenômenos distintos. De todo modo, essas me parecem, justamente, as possibilidades abertas pelas categorias propostas: ao conformarem um determinado campo heurístico compartilhado em uma agenda de questôes, que orientam e controlam de algum modo seus usos, abrem-se também à vulnerabilidade empírica e, com isso, ao seu refinamento e à consequente complexificação, sempre perspectivada, de nossa inteligibilidade do mundo.

\section{Tantos diagnósticos são sintomas de quê?}

As duas propostas aqui discutidas, como disse de início, se inserem e se reconhecem em uma dinâmica ao mesmo tempo disciplinar e político-social. Ambas tomam posiçóes em relação a essas dimensôes, e essas posiçôes manifestam-se não apenas no que é dito, mas no como é dito. Representam, assim, duas formas de conceber e elaborar linguagens teóricas de descrição do mundo, gerando conotaçóes distintas às suas categorias e às suas leituras.

De todo modo, é preciso reconhecer que talvez a situação mais paradoxal e difícil em uma investigação sobre o tempo e, mais especificamente, sobre a historicidade é que eles não podem ser percebidos como objetos autônomos. Só se pode falar deles falando de outra coisa. Afinal, o tempo não é nada mais do que a forma interna de processos e experiências. Assim, querer abstrair e universalizar o tempo e a historicidade enquanto objetos é cair em um vão linguístico de difícil saída. ${ }^{31}$ Mesmo as linguagens teóricas de descrição do mundo vigentes atualmente na física, como ressaltou Étienne Klein, lidam com ao menos três aspectos muito distintos do tempo, de acordo com a especificidade dos processos que descrevem. Como afirma Klein: "A dificuldade advém do fato de não se poder falar dele (do tempo) sem falar também de todo o resto. $\mathrm{O}$ tempo não é uma parte isolada do pensamento. Nunca se desnuda. Por tudo isto não será vão pretender 'dar um sentido mais puro a esta palavra da tribo', como diz Mallarmé?”. ${ }^{32}$ Apesar disso, boa parte

\footnotetext{
${ }^{29}$ HUYSSEN, Andreas. Geografias do modernismo em um mundo globalizante. In: Culturas do passado-presente. Modernismos, artes visuais, políticas da memória. Rio de Janeiro: Contraponto, 2014.

${ }^{30}$ JORDHEIM, Helge. Multiple Times and the work of synchronization. History and Theory, v. 53, n. 4, 2014.

${ }^{31}$ BOUVERESSE, Jacques. Les “énigmes” du temps. In: Essais III. Wittgenstein et les sortiléges du langage. Paris: Ágone, 2003.

${ }^{32}$ KEIN, Étienne. O tempo. Lisboa: Instituto Piaget, 1995, p. 77.
} 
da filosofia do século XX se ocupou justamente em tentar purificá-lo de suas expressóes cotidianas inautênticas, desvelando o enigma de sua essência. Os historiadores, por sua vez, se acostumaram a usá-lo na maior parte das vezes como uma ferramenta de classificação. Nossas grades curriculares e a maior parte de nossas especializaçôes ainda carregam essa herança. Falar do tempo como algo autônomo ou usá-lo como uma classificação supostamente neutra, afinal, não tem nada de inocente, pois sabemos (ou deveríamos) que a escrita da história é, ela mesma, uma das formas de temporalização presentes na sociedade. Aí se insere, portanto, uma política da história. Ela implica, assim, ou pode implicar, os atos contíguos de classificação e de desclassificação do tempo, asseverando quem é ou não "mais contemporâneo" ou, ainda, para brincar com a fórmula koselleckiana: quem é o "não contemporâneo do contemporâneo".

Algo que talvez se mostre fundamental nesse interesse atual pela temporalidade é, justamente, uma maior preocupação e prudência com as linguagens através das quais podemos falar e dar a ver as formas temporais implicadas em distintas experiências históricas, tanto "presentes" como "passadas". Inclusive na que estamos inseridos, enquanto historiadores. Nesse sentido, mais importante que o uso de uma ou outra categoria específica, que tendem a se tornar facilmente quadros de ferro hermenêuticos ou simplesmente emblemas intelectuais, é a forma de raciocínio que elas implicam e, consequentemente, a forma de dizer. Se não podemos falar do tempo senáo falando de outra coisa, é importante não esquecermos do que estamos falando, e como. Ou, ainda, para poder falar das diferentes formas do tempo, temos que considerar também as possibilidades e os limites das formas de nossa linguagem.

Se a história disciplinar já ocupou um lugar privilegiado como prática de temporalização da sociedade, mediante a hegemonia das vinculaçóes acadêmicas e escolares, hoje ela se vê convivendo com uma imensa variedade de discursos históricos, nos mais diversos formatos e linguagens, e que implicam formas temporais igualmente distintas. Nesse contexto, mais do querer renovar seu caráter profético, como enunciadora da "ordem do tempo" (com toda a ambiguidade da expressáo), talvez caiba à disciplina histórica e às ciências humanas, de modo geral, pensar essas formas e pensar com essas formas, suas possibilidades e limites, suas implicaçôes éticas, seus pressupostos epistemológicos, suas linguagens e seu caráter performativo. Mas para isso é necessário atentar, igualmente, tanto para os limites como para a pluralidade condicional de toda linguagem historiográfica e das humanidades. $\mathrm{Ou}$, como afirmou Wittgenstein: "Pois só podemos escapar à injustiça ou ao vazio das nossas asserções se apresentarmos o modelo como aquilo que é, como objecto de comparação - como, por assim dizer, um padráo de medida, e náo como um preconceito ao qual a realidade deve corresponder. (O dogmatismo em que caímos tão facilmente ao fazer filosofia)". ${ }^{33}$

\footnotetext{
33 WITTGENSTEIN, Ludwig. Philosophical investigations. Oxford: Blackwell, 2001, p. 43. "For we can avoid ineptness in our assertions only by presenting the model as what it is, as an object of comparaison - as, so to speak, a measuring-rood; not as a preconceived idea to which reality must correspond. (The dogmatism into wich we fall so easily in doing philosophy)". Grifos no original.
} 


\section{Referências bibliográficas}

ARAÚJO, Valdei Lopes de. A história da historiografia como analítica da historicidade, História da Historiografia, Ouro Preto, n. 12, 2013.

BANTIGNY, Ludivine; DELUERMOZ, Quentin (Orgs.). Historicités du 20 siècle. Coexistence et concurrence des temps, Vingtième Siècle. Revue d'Histoire, n. 117, jan./mar. 2013.

BLOCKER, Déborah.; HADDAD, Elie. Le présent comme inquiétude: temporalités, écritures du temps et actions historiographiques, Revue d'Histoire Moderne et Contemporaine, n. 53, 2006.

BLUMENBERG, Hans. Descripción del ser humano. México: Fondo de Cultura Económica, 2010.

BOUVERESSE, Jacques. Les “énigmes” du temps. In: BOUVERESSE, Jacques. Essais III. Wittgenstein et les sortiléges du langage. Paris: Ágone, 2003.

DELACROIX, Christian. Genealogie d'une notion. In: DELACOROIX, Christian; DOSSE, François; GARCIA, Patrick (Orgs.). Historicités. Paris: La Découverte, 2009.

GROOT, Jerome de. Consuming history. Historians and Heritage in Contemporary Popular Culture. Abingdon: Routledge, 2008.

GUMBRECHT, Hans Ulrich. Depois de aprender com a história. In: GUMBRECHT, Hans Ulrich. Em 1926. Vivendo no limite do tempo. Rio de Janeiro, Record, 1999.

. Cascatas da modernidade. In: Modernização dos sentidos. São Paulo: Editora 34, 1998.

- Production of presence. What meaning cannot convey. Stanford: Stanford Universitty Press, 2004.

. Pirâmides do espírito. Sobre a rápida ascensão, as dimensões invisíveis e o súbito esmorecimento do movimento da história dos conceitos. In: Graciosidade e estagnação. Ensaios escolhidos. Rio de Janeiro: Contraponto/PUC-Rio, 2012.

. Depois de 1945. Latência como origem do presente. São Paulo: Unesp, 2012.

HARTOG, François. Regimes de historicidade. Presentismo e experiências do tempo. Belo Horizonte: Autêntica, 2013.

. A testemunha e o historiador. In: HARTOG, François. Evidência da História. O que os historiadores veem. Belo Horizonte: Autêntica, 2011.

. Anciens, modernes, sauvages. Paris, Galaade, 2005.

HEIDEGGER, Martin. Construir, habitar, pensar. Córdoba: Alción, 1997.

HUBERT, Henri. Estudo sumário da representação do tempo na religião e na magia. In: BENTHIEN, Rafael Faraco; PALMEIRA, Miguel; TURIN, Rodrigo (Orgs.). Estudo sumário da representação do tempo na religião e na magia. Coleção Durkheiniana, v. II. São Paulo: Edusp, 2016. 
HUYSSEN, Andreas. Geografias do modernismo em um mundo globalizante. In: Culturas do passado-presente. Modernismos, artes visuais, políticas da memória. Rio de Janeiro: Contraponto, 2014.

JORDHEIM, Helge. Multiple Times and the work of synchronization, History and Theory, v. 53, n. $4,2014$.

KEIN, Étienne. O tempo. Lisboa: Instituto Piaget, 1995, p. 77.

KLEINBERG, Ethan. Introduction: the new metaphysics of time. History and Theory, virtual issue, n. 1, August, 2012.

LORENZ, Chris; BEVERNAGE, Berber (Orgs.). Breaking up time. Negotiating the borders between present, past and future. Gottingen: Vandenhoeck \& Ruprecht, 2013.

LORENZ, Chris. If You're So Smart, Why Are You under Surveillance? Universities, Neoliberalism, and New Public Management, Critical Inquiry, n. 38, 2012.

MUDROVCIC, María Inés. Regímenes de historicidad y regímenes historiográficos: del pasado histórico al pasado presente. Historiografias, Revista de Historia y Teoría, n. 5, 2013.

NICOLAZZI, Fernando. A História entre tempo: François Hartog e a conjuntura historiográfica contemporânea, História: Questôes \& Debates, Curitiba, n. 53, jul./dez. 2010. NOIRET, Serge. História pública digital. Liinc em Revista, Rio de Janeiro, v. 11, n. 1, p. 28-51, maio 2015.

PASSERON, Jean-Claude. O raciocínio sociológico. O espaço não popperiano do raciocínio natural. São Paulo: Vozes, 1995.

PEREIRA, Mateus Henrique de Faria; MATA, Sérgio da. Introdução: Transformações da experiência do tempo e pluralização do presente In: VARELLA, Flávia; MOLLO, Helena M; PEREIRA, Mateus H. de Faria; MATA, Sérgio (Orgs.). Tempo presente e usos do passado. Rio de Janeiro: FGV, 2012.

REVEL, Jacques. Recursos narrativos e conhecimento histórico. In: História e Historiografia. Exercícios Críticos. Curitiba: Editora UFPR, 2010.

ROSA, Hartmut. Accéleration. Une critique sociale du temps. Paris: La Découverte, 2010. ROSA, Hartmut; SCHEUERMAN, William E. (Orgs.). High-speed society. Social acceleration, power and modernity. Philadelphia: Pennsylvania University Press, 2009.

RUNIA, Eelco. Presence. In: Moved by the Past. Discontinuity and historical mutation. Nova York: Columbia University Press, 2014.

WITTGENSTEIN, Ludwig. Philosophical investigations. Oxford: Blackwell, 2001. 